\title{
The necessity of using high quality orthoses in rehabilitation medicine
}

\author{
Elena Amaricai* \\ Department of Rehabilitation, Physical Medicine and Rheumatology, "Victor Babeş" University of \\ Medicine and Pharmacy, Eftimie Murgu 2, Timișoara, Romania
}

\begin{abstract}
In rehabilitation medicine there is increasing need of using high quality orthoses that can provide either good stability of the joint or good correction of the postural defect. The advantages of using orthoses that are in the same time hypoallergenic, lightweight, flexible, resistant and durable over time should be considered when prescribing them in clinical practice. This study presents different types of orthoses and the necessity of proper selection of materials when choosing the best ones. We included 34 patients diagnosed with different musculoskeletal conditions (thoracic and thoraco-lumbar scoliosis, genu valgum deviation and rheumatoid arthritis) that required the use of special orthoses (thoraco-lumbar braces, knee or hand orthoses). Patients were asked to complete a questionnaire regarding the quality of the orthoses that they have been used. The following characteristics of an orthosis should be considered when choosing the right one: easily wearable, comfortable, offering good stability of a joint, high quality, lightweight, hypoallergenic and resistant.
\end{abstract}

\section{Introduction}

In rehabilitation medicine the use of orthoses is well-known, widespread and well recognized by the health professionals. There are a great number of pathologies that benefit from the advantages of orthotics such as orthopaedic and posttraumatic pathologies, rheumatic diseases and neurologic conditions.

The most important aim when referring to orthotics and rehabilitation is the regaining of normal shape and function after a certain disease or injury [1].

Using the $3 \mathrm{D}$ printing processes in orthosis manufacturing procedures, new prototypes and functional devices could be developed in order to improve the patient's quality of life [2]. The scanning of an image is correlated to real-time patient's functioning of the addressed part of the body [3].

The properties of bio-composite polymers lead to the possibility of developing new models of equipment and instruments used in medical rehabilitation. This takes into account their nontoxic properties and resistance to impact and external forces creating patient-tailored devices [4].

\footnotetext{
*Corresponding author: ama.elena@gmail.com
} 
The objective of our study was to point out the necessary features of an orthosis used in patients suffering from musculoskeletal diseases that needed also an orthotic device in their treatment plan.

\section{Material and method}

Our study included 34 patients suffering from different musculoskeletal conditions that require the use of special orthoses.

24 of our patients were children, aged between 11 and 16 years old. 20 patients had moderate scoliosis (thoracic or thoraco-lumbar types). These types of scoliosis required besides the physical exercise programme the use of a thoraco-lumbar brace in order to correct the spinal deviations. 4 patients had knee deformities (genu valgum) and needed the use of a knee orthosis.

Our study also included 10 patients (aged between 39 and 71 years) diagnosed with a rheumatic pathology, namely rheumatoid arthritis. They presented different types of upper limbs deviations and had to use a special hand orthoses.

The patients were asked to complete a questionnaire regarding the orthoses that they have been used (see Table 1).

Descriptive statistics were calculated as median and interquartile range for questionnaire scores. The questionnaire total score ranges from 50 (maximum, best result) to 10 (minimum, worst result). The questionnaire scores according to pathology were expressed as mean and standard deviation.

Unpaired t-test was performed to compare the questionnaire results in adults and paediatric patients. Correlation tests were performed by using Pearson correlation test for normally distributed data. All statistical analyses were done using GraphPad Prism 5.0 for Windows.

Table 1. Questionnaire regarding the use of orthoses.

\begin{tabular}{|l|c|c|c|c|c|}
\hline & Always & Very often & Sometimes & Rarely & Never \\
\hline 1. Is your orthosis easy to wear? & 5 & 4 & 3 & 2 & 1 \\
\hline $\begin{array}{l}\text { 2. Do you feel comfortable when } \\
\text { wearing your orthosis? }\end{array}$ & & & & & \\
\hline $\begin{array}{l}\text { 3. Does your orthosis offer you a } \\
\text { good stability? }\end{array}$ & & & & & \\
\hline $\begin{array}{l}\text { 4. Does your orthosis offer you a } \\
\text { good mobility? }\end{array}$ & & & & & \\
\hline $\begin{array}{l}\text { 5. Do you wear your orthosis at } \\
\text { school? (for children) } \\
\text { Do you wear your orthosis at } \\
\text { work? (for adults that are active } \\
\text { professionals) }\end{array}$ & & & & & \\
\hline $\begin{array}{l}\text { 6. Do you wear your orthosis } \\
\text { during the night? }\end{array}$ & & & & & \\
\hline
\end{tabular}


Table 1. Questionnaire regarding the use of orthoses (cont).

\begin{tabular}{|l|c|c|c|c|c|}
\hline & $\begin{array}{c}\text { Strongly } \\
\text { agree }\end{array}$ & Agree & $\begin{array}{c}\text { I do not } \\
\text { know }\end{array}$ & Disagree & $\begin{array}{c}\text { Strongly } \\
\text { disagree }\end{array}$ \\
\hline $\begin{array}{l}\text { 7. Do you consider important to } \\
\text { wear a high quality orthoses for } \\
\text { your problem? }\end{array}$ & 5 & 4 & 3 & 2 & 1 \\
\hline $\begin{array}{l}\text { 8. Do you consider important to } \\
\text { have a lightweight orthosis? }\end{array}$ & & & & & \\
\hline $\begin{array}{l}\text { 9. Do you consider important to } \\
\text { have a hypoallergenic orthoses? }\end{array}$ & & & & & \\
\hline $\begin{array}{l}\text { 10. Do you consider important to } \\
\text { have a durable and resistant } \\
\text { orthoses? }\end{array}$ & & & & & \\
\hline
\end{tabular}

\section{Results}

All 34 patients considered their orthosis to be easily wearable. 25 patients $(73.5 \%)$ feel rarely or never comfortable with their orthosis. None of them considered their orthotic device to be very often or always comfortable. Only adult patients with rheumatoid arthritis agree feeling sometimes comfortable when wearing their hand orthosis. $94 \%$ of the patients think that their device provides them a good stability. In contrast, only $8 \%$ consider that orthosis offer a better mobility.

11 from the 24 children wear their spinal orthosis at school. All adult patients with rheumatoid arthritis who are active professionals wear their hand orthosis at work. $88 \%$ of all 34 patients also wear their orthotic device during the night-time.

Regarding the quality of their orthoses, $100 \%$ of patients consider that it is very important to have a high quality one. At the same time, they all consider extremely important to have a lightweight and hypoallergenic orthosis. All the 10 adult patients think that having a resistant and durable over time orthosis is important. Only half of the children consider this last feature to be important. That can be due to the fact that they are in their growth period and they have to change their orthoses over time, frequently every year.

The differences among the musculoskeletal diseases and the total questionnaire scores are presented in Table 2 .

Table 2. Median total questionnaire score in the assessed musculoskeletal conditions.

\begin{tabular}{|l|c|c|}
\hline & Total questionnaire score & \multicolumn{1}{|c|}{$\begin{array}{c}\text { Range of } \\
\text { total questionnaire score }\end{array}$} \\
\hline $\begin{array}{l}\text { Scoliosis } \\
(\mathrm{n}=20)\end{array}$ & $36.35 \pm 3.06$ & $32-41$ \\
\hline $\begin{array}{l}\text { Knee deformity (genu } \\
\text { valgum) }(\mathrm{n}=4)\end{array}$ & $34.25 \pm 2.2$ & $32-37$ \\
\hline $\begin{array}{l}\text { Rheumatoid arthritis } \\
(\mathrm{n}=10)\end{array}$ & $42.9 \pm 0.73$ & $42-44$ \\
\hline
\end{tabular}

$n$ : number of patients.

When comparing the score results in adults and paediatric patients we noticed significantly better questionnaire score in rheumatoid arthritis patients $(p<0.0001)$. There was a strong direct correlation between patients' age and the total questionnaire score $(\mathrm{p}<0.0001 ; \mathrm{r}=0.81)$ (see Figure 1$)$. 


\section{Correlation age-total score}

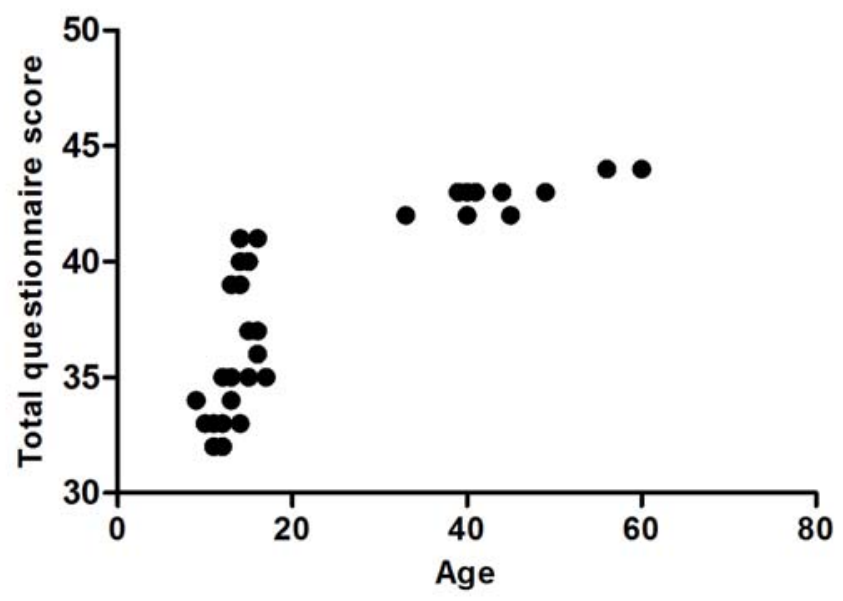

Fig. 1. Correlation between patients' age and total questionnaire score.

\section{Discussions}

Orthotics proved over time to provide a better recovery of a patient with a disability, helping him/her to regain the lost hand function, spinal alignment, joint positions or gait [5, $6]$.

When choosing a type of orthosis the rehabilitation specialist must have in view both its characteristics and disadvantages. There are differences in the mechanical properties that are due to the choice of materials. The measurement of stiffness and neutral angle must be done when making a patient tailored device [7].

In rehabilitation medicine children that are using orthoses must wear them for long period of time (for months and even for years in some cases). Children adherence for their orthotic device is extremely important for achieving the final outcome, namely the correction of their musculoskeletal deformities. That is why having a high quality orthosis contributes to the rehabilitation process.

When referring to high quality orthoses we have in view not only their technical features (hypoallergenicity, weight, flexibility, resistance and durability over time), but also those characteristics the patients consider to be important. The amount of time patients wear their orthoses is also related to the orthotic device quality.

Some patients also include the orthosis price in the assessment of a certain type of device, taking into account that a higher price is often associated with a better quality.

Although some present scientific studies do not provide sufficient arguments in order to draw strong conclusions on effectiveness and cost-effectiveness of orthotic devices [8], we sustain the importance of using high quality orthoses in rehabilitation medicine. There are many researches that point out the utility of orthotic intervention in scoliosis, knee deformities and rheumatoid arthritis [9-12].

The limitations of our study were the following: small number of patients, patients with different types of musculoskeletal disorders, unequal repartition of patients (20 patients with scoliosis, 10 patients with rheumatoid arthritis and 4 patients with genu valgum deformity), inclusion of both adult patients and paediatric patients (older than 9 years). 


\section{Conclusions}

Our study pointed out the importance of using good quality orthotic devices when treating patients with musculoskeletal disorders. This has in view both adult patients suffering from a rheumatic inflammatory disease, namely rheumatoid arthritis, and paediatric patients, namely children and adolescents diagnosed with moderate types of scoliosis or knee deformities such as moderate types of bilateral genu valgum.

In order to achieve the best results with an orthotic intervention, this device such be easily wearable, comfortable, lightweight, hypoallergenic and with a good resistance. It should offer either a good stability or a good mobility. The orthosis should be worn both during the night and daytime (at work or at school).

We have in view to continue our study with future research that will also imply the technicians that are designing and producing the orthoses. This collaboration between medical staff and technical staff is extremely important in order to achieve the best functional results and to obtain a tailored device for each patient.

\section{References}

1. M.M. Lusardi, M. Jorge, C.C. Nielsen, Orthotics and Prosthesis in Rehabilitation (Elsevier Saunders, 2013)

2. R.S. Miclăuș, A. Repanovici, N. Roman, Mater Plast 54, 98-102 (2017)

3. I. Virag, L. Stoicu-Tivadar, E. Amăricăi, 9th IEEE International Symposium on Applied Computational Intelligence and Informatics, 355-359 (2014)

4. C. Opran, D. Cotoros, N. Roman, A. Repanovici, R.S. Miclăuş, Mater Plast 54, 438442 (2017)

5. O. Suciu, R.R. Onofrei, A.D. Totorean, S.C. Suciu, E.C. Amaricai, Gait Posture 49, 184-189 (2016)

6. D. Tanasie, L. Catan, D. Popa, S. Hategan, E. Amaricai, Rev Chim 67, 1023-1027 (2016)

7. E. Ridgewell, F. Dobson, T. Bach, R. Baker, Prosthet Orthot Int 34, 129-145 (2010)

8. A. Healy, S. Farmer, A. Pandyan, N. Chockalingam, PLoS One 13, e0192094 (2018)

9. R.M. Thompson, E.W. Hubbard, C.H. Jo, D. Virostek, L.A. Karol, J Bone Joint Surg Am 99, 923-928 (2017)

10. R.E. Iacob, A. Boglut, O.C. Miloicov Bacean, E. Amaricai, S. Cerbu, S. Bolintineanu, L. Grigorita, C. Citu, E. Bernad, I. Petre, G. Furau, Mater Plast 53, 391-393 (2016)

11. T. Fikentscher, H.R. Springorum, J. Grifka, J. Götz, Z Rheumatol 76, 245-258 (2017)

12. E. Sadeghi-Demneh, S. Forghany, P. Onmanee, U. Trinler, M.P. Dillon, R. Baker, The influence of standards and clinical guidelines on prosthetic and orthotic service quality: a scoping review, Disabil Rehabil, 1-8 (2017) 